\title{
DELETION OF TWENTY SEVEN NUCLEOTIDES WITHIN EXON 11 OF THE BAND 3 GENE IDENTIFIED IN OVALOCYTOSIS IN LOMBOK ISLAND, INDONESIA
}

\author{
Haryanto Alimsardjono, ${ }^{1}$ Indri Safitri Mukono, ${ }^{2}$ \\ Yoes Prijatna Dachlan, ${ }^{2}$ and Masafumi MATSUO ${ }^{\mathrm{I}, *}$ \\ ${ }^{1}$ Division of Genetics, International Center for Medical Research, Kobe University \\ School of Medicine, 7-5-1 Kusunoki, Chuo-ku, Kobe 650, Japan \\ 2 Tropical Disease Research Center, Airlangga University, Jl. Mayjen \\ Prof. Dr. Moestopo 47, Surabaya 60131, Indonesia
}

Summary This study reports the molecular characterization of ovalocytosis in Lombok Island, Indonesia. The analysis of genomic DNA by polymerase chain reaction shows that all 21 ovalocytotic individuals have two amplified products of different size from a region encompassing exon 11 of the band 3 gene. The sequence of the larger product matched perfectly with that of normal individuals. In the sequence of the smaller product, 27 nucleotides within exon 11 were deleted. The heterozygous presence of the deletion identified in other parts of Southeast Asia was confirmed in patients with ovalocytosis in an isolated island of eastern Indonesia.

Key Words ovalocytosis, erythrocyte, band 3, deletion

Southeast Asian ovalocytosis (SAO) is a hereditary form of elliptocytosis resulting in rigid, oval-shaped erythrocytes resistant to invasion by malarial parasites. The molecular basis for SAO was recently identified as a heterogeneous presence of an altered erythrocyte band 3 protein which lacked 9 amino acids (residues 400-408) at the boundary between the cytoplasmic and membrane domains (Jarolim et al., 1991). The same mutation has been described in ovalocytotic individuals of Mauritius (Schofield et al., 1992), Malaysia, the Philippines, and Papua New Guinea (Tanner et al., 1991; Mohandas et al., 1992). The same mutation was again identified in individuals with ovalocytosis from a western island in Indonesia (Takeshima et al., 1994). However, no mutation study

Received August 12, 1996; Revised version accepted December 12, 1996.

* To whom correspondence should be addressed. 


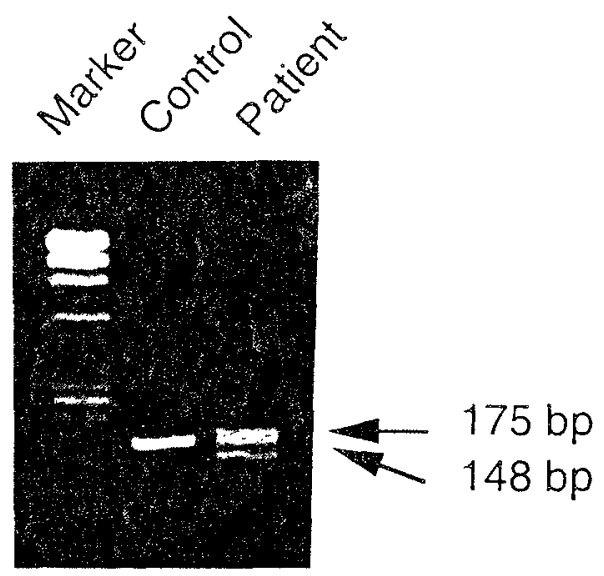

Fig. 1. Amplification of genomic DNA encompassing exon 11 . The exon 11 encompassing region was amplified by using a set of primers (forward: $5^{\prime}$ GGGCCCAGATGACCCTCTGC-3'; reverse: 5'-GCCGAAGGTGATGGCGGGTG-3') and separated by $3 \%$ agarose gel electrophoresis (Takeshima et al., 1994). Only one band corresponding to $175 \mathrm{bp}$ was visualized after amplification of the control DNA. The ovalocytosis DNA gave this same product as well as the smaller 148 bp product.

has ever been conducted among affected individuals from the eastern part of Indonesia. This paper describes the results of molecular analysis done on ovalocytotic individuals of a different Indonesian ethnic source. Twenty-one non-related individuals from Lombok Island in eastern Indonesia were diagnosed to have ovalocytosis based on the criteria used by Takeshima et al. (1994). DNA samples were extracted from blood cells of these subjects. Molecular analysis of the band 3 gene was the performed as described before (Takeshima et al., 1994). A 175 bp long region spreading from nt. 1098 to nt. 1272 of band 3 protein cDNA (numbering was based on that used by Tanner et al. (1988)) was amplified (Jarolim et al., 1991). Only one band corresponding to $175 \mathrm{bp}$ in length was visualized on the agarose gel after ethidium bromide staining for the control DNA (Fig. 1). Meanwhile, 2 narrowly separated bands were obtained from the ovalocytosis DNA. One was slightly smaller than the single band derived from the control and the other comigrating with the control (Fig. 1). All 21 subjects revealed the same results.

The sequencing result disclosed that the smaller amplified product had a deletion of 27 nucleotides extending from nt. 1198 to 1224 . There was no other nucleotide difference noted from the wild sequence (Fig. 2). The deleted 27 nucleotides corresponded to codons 400 to 408 of the band 3 protein. These findings confirmed that individuals with ovalocytosis from Lombok Island are also heterozygous for the abnormal band 3 protein.

It has been reported for both Papua New Guinea and Bangka Island in 


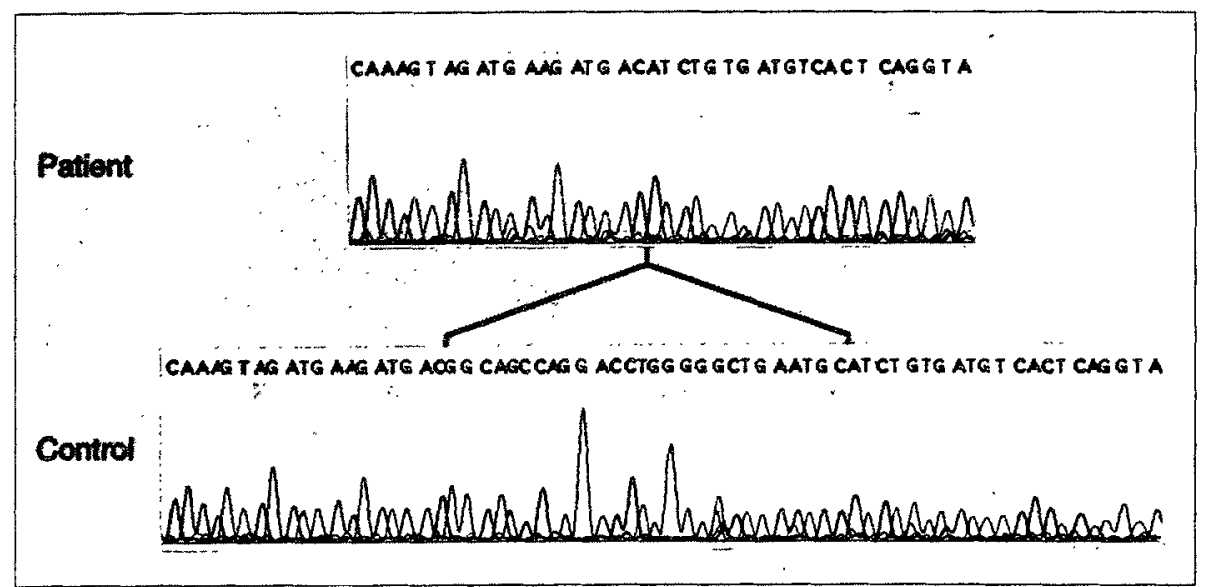

Fig. 2. Nucleotide sequence of part of the amplified product. After inserting the amplified product into pT7Blue(R)T-vector, the sequence of the subcloned DNA was determined using an atuomated DNA sequencer (model 373A; Applied Biosystems, Foster City, CA). Two types of DNA clone were obtained from PCR-amplified ovalocytosis samples. One of them corresponded to control band 3 (lower). The other type of clone which represents the abnormal ovalocytic band 3 differed from the normal because of the deletion of 27 nucleotides (upper).

western Indonesia that a deletion of 27 nucleotides in the band 3 gene is responsible for ovalocytosis. A sea of information can still be obtained for molecular genetic studies on ovalocytotic individuals from the several islands between this regions. Lombok Island, located in the eastern part of Indonesia, is still an endemic malarious region. It is isolated from the Island of Java. We focused our molecular analysis of ovalocytosis on this isolated island. True enough, we identified the same mutation in all 21 cases of ovalocytosis.

Hemoglobinopathies (including $\alpha$ - and $\beta$-thalassemias and sickle cell anemia), glucose 6 phosphate dehydrogenase deficiency, and ovalocytosis are very common genetic diseases in endemic malarious area. Because genetic mutations can provide resistance to malarial infection, malarial selection is suggested to determine the frequency of genetic disease in human population (Flint et al., 1993). Our results confirmed that ovalocytosis in an isolated Indonesian island presents with the same amino acid deletion of the band 3 protein as reported in other countries (Tanner et al., 1991; Mohandas et al., 1992; Schofield et al., 1992; Takeshima et al., 1994). This is the second example of a genetic disease that is common in endemic malarious regions and is caused by only one kind of mutation. If it is true that only one mutation is common in areas from Melanesia to Mauritius, what factor may provide such phenomenon? It is conceivable that $\mathrm{SAO}$ has a single origin and distribution of SAO goes alongside with the

Vol. 42, No. 1, 1997 
migration of people (Schofield et al., 1992; Liu et al., 1994).

Acknowledgments We would like to extend our gratitude to Dr. Agus Sutanto, Director of West Nusa Tenggara Province Health Department, Indonesia for his encouragement and Miss A. Maruyama for her help in preparing the manuscript. This work was supported by grants from the Ministry of Education, Science, Sports and Culture of Japan.

\section{REFERENCES}

Flint J, Harding RM, Clegg JB, Boyce AJ (1993): Why are some genetic diseases common? Hum Genet 91: 91-117

Jarolim P, Palek J, Amato D, Hassan K, Sapak P, Nurse GT, Rubin HL, Zhai S, Sahr KE, Liu S-C (1991): Deletion in erythrocyte band 3 gene in malaria-resistant Southeast Asian ovalocytosis. Proc Natl Acad Sci USA 88: 11022-11026

Liu S-C, Jarolim P, Rubin HL, Palek J (1994): The homozygous state for the band 3 protein mutation in Southeast Asian ovalocytosis may be lethal. Blood 84: 3590-3598

Mohandas N, Winardi R, Knowles D, Leung A, Parra M, George E, Conboy J, Chasis J (1992): Molecular basis for membrane rigidity of hereditary ovalocytosis. A novel mechanism involving the cytoplasmic domain of band 3. J Clin Invest 89: 686-692

Schofield AE, Tanner MJA, Pinder JC, Clough B, Bayley PM, Nash GB, Dluzewski AR, Reardon DM, Cox TM, Wilson RJM, Gratzer WB (1992): Basis of unique red cell membrane properties in hereditary ovalocytosis. I Mol Biol 223: 949-958

Takeshima Y, Sofro AS, Suryantoro P, Narita N, Matsuo M (1994): Twenty seven nucleotides deletion within exon 11 of the erythrocyte band 3 gene in Indonesian ovalocytosis. Jpn $J$ Human Genet 39: 181-185

Tanner MJA, Martin PG, High S (1988): The complete amino acid sequence of the human erythrocyte membrane anion-transport protein deduced from the cDNA sequence. Biochem J 256: 703-712

Tanner MJA, Bruce L, Martin PG, Reardon DM, Jones GL (1991): Melanesian hereditary ovalocytes have a deletion in red cell band 3. Blood 78: 2785-2787 